\title{
RELATIVNA AVTONOMIJA GLASBE: PRIMER LJUBLJANSKEGA DNEVNIKA 1951-1961
}

\author{
LEON STEFANIJA \\ Filozofska fakulteta Univerze v Ljubljani
}

Izvleček: Namen prispevka je podati podobo glasbene publicistike in vprašanja uporabnosti in avtonomije glasbe v petdesetih letih 20. stoletja, kot se kaže skozi analizo Ljubljanskega dnevnika $v$ letih 1951-61. Z osredotočanjem na najbolj razširjeni dnevni časopis $v$ totalitarnem obdobju slovenske novejše zgodovine avtor obravnava »relativno avtonomijo " glasbe $s$ tremi tematskimi sklopi, ki postavljajo $v$ središč pozornosti: 1. skladateljsko avtonomijo, 2. avtonomijo glasbe kot družbene institucije in 3. poslušalčevo avtonomijo.

Ključne besede: estetika glasbe, sociologija glasbe, funkcije glasbe, slovenska glasba
Abstract: Through the analysis of musical entries in the newspaper Ljubljanski dnevnik and a discussion of what appear to be the main topoi of that time, the article offers an insight into the relations between three sets of questions connecting (and, at the same time, revealing differences between) the notions of musical autonomy and function: 1. the composer's autonomy, 2. the autonomy of music as a social institution and 3. the autonomy of the listener.

Keywords: aesthetics of music, sociology of music, functions of music, Slovenian music

\section{Namen prispevka}

Namen prispevka je orisati vprašanja o funkciji glasbe v petdesetih letih 20. stoletja, kot se kaže skozi analizo Ljubljanskega dnevnika v letih 1951-61, ${ }^{1}$ ki doslej ni bil deležen sistematične muzikološke raziskave.

V desetletju po izidu prve številke Ljubljanskega dnevnika (julij 1951) se je začelo za čas po drugi svetovni vojni na Slovenskem tako značilno tematiziranje »uporabnosti« glasbe vedno bolj nejasno prepletati in postopoma uklanjati pogledom, ki sodijo k ideji glasbeno avtonomnega. Tako je besedilo predvsem prispevek k pojmu »relativne avtonomije glasbe, saj obravnavano gradivo ne ponuja možnosti za dvom o duhovni uporab-

1 Izbor tega časopisa za analizo glasbene publicistike na temo avtonomije in uporabnosti glasbe temelji na dveh dejstvih, enem stvarnem in drugem zgodovinskem. Prvo je to, da je bil Ljubljanski dnevnik v petdesetih letih 20. stoletja edini dnevni časopis, ki je poleg Slovenskega poročevalca (kasneje: Delo) bolj ali manj redno in v primerjavi z drugimi časopisi malo bolj izrazito - čeprav zdaleč ne skrbno načrtovano - sistematično prinašal tudi prispevke o glasbi. Drugi razlog za izbor izhaja iz pospešenega procesa spreminjanja kulturnih in političnih okoliščin, ki jih ta časopis odseva dovolj natančno. 
nosti (ali, s parafrazo Adorna, o »funcijskosti metafizičnega«) sicer pragmatično zgolj v nekaterih primerih uporabnega estetskega kapitala glasbe.

Glavni cilj prispevka je začrtati razmerja med tremi spoznavno ločenimi sklopi vprašanj, ki zadevajo pojem glasbeno avtonomnega in povezujejo poglede o avtonomiji in uporabnost glasbe (razkrivajoč obenem tudi razlike med njimi). Gre za tematske sklope, ki postavljajo v središče pozornosti: 1. skladateljsko avtonomijo, 2. avtonomijo glasbe kot družbene institucije in 3. poslušalčevo avtonomijo.

\section{Dejstva}

\section{Publicistične zvrsti o glasbi}

Kakšne pozornosti je bila deležna glasba v Ljubljanskem dnevniku, nakazuje dinamika skupno več kot 1302 vpisov o glasbi po posameznih sezonah in zvrsteh pisanja v preglednici (Priloga 1). ${ }^{2}$

Ljubljanski dnevnik je v povprečju ohranil aktualne refleksije o koncertni ponudbi - torej zlasti kritike (delno tudi predstavitve) - za nekaj manj kot polovico (kritike se nanašajo na $47 \%$ ) koncertnih dogodkov. Toda izrazita nihanja med številoma kritik in koncertov za posamezna leta (med več kot 80 \% za sezono 1954/55 in manj kot $15 \%$ za naslednji sezoni), precej nejasno kadrovanje piscev in majhno število esejističnih prispevkov nakazujejo stihijsko glasbeno politiko časopisa, v katerem sicer prevladujejo kritike koncertov, sledijo predstavitve skladateljev, glasbenih del ali glasbenih dogodkov, notice in najave.

\section{Delež besedil o glasbi}

Razmerje med glasbenimi in drugimi umetnostnimi prispevki je komajda mogoče natančneje določiti - posamezne tematske rubrike so se začele jasneje oblikovati šele v drugi polovici petdesetih, pa še takrat bolj priložnostno kot ne. Povrh se zapisi o glasbi pojavljajo med besedili, ki nimajo nikakršne povezave z umetnostjo, mestoma tudi nič s kulturo v širšem smislu. Zato kaže na podlagi seznama besedil o glasbi v Ljubljanskem dnevniku, priloženega na koncu, v grobem sklepati, da (kljub spremenljivosti) glasba v najboljšem primeru ni dobila več kot približno petine prostora, namenjenega kulturi in umetnosti.

\section{Pisci}

Izstopata dva podatka dinamike objav besedil o glasbi: nihanje števila objav in deležev po posameznih publicističnih zvrsteh. Verjetno je spreminjanje števila prispevkov o glasbi

2 V preglednici je tudi več notic in najav pod enim naslovom štetih kot en vpis, niso pa posebej šteti vpisi glasbenih oddaj RTV sporeda, ki je v obliki priloge izhajal leta 1958 do marca 1959, čeprav je tudi tu objavljena vrsta predstavitev posameznih glasbenikov, glasbenih del, izvajalskih teles ipd. 
in zvrsti besedil sledilo kadrovskim rešitvam v časniku. Pisci o glasbi - v obravnavanem obdobju lahko naštejemo 122 različnih podpisov - so bili pogosto podpisani samo z inicialkami (med njimi je nekaj težko ugotovljivih identitet), čeprav je samo en avtorski zapis nepodpisan (Priloga 2). Največkrat podpisani glasbeni publicist v celotnem desetletju, Rafael Ajlec, nekaj let (med 7. 5. 1953 in 23. 5. 1959) sploh ni objavljal v Ljubljanskem dnevniku. Tako je v sezoni 1953/54 najpogosteje podpisan glasbenik Pavle Kalan, v sezoni 1954/55 in 1955/56 Jerko Bezić in J. G. (za kratek čas tudi Borut Loparnik). S sezono 1956/57 in 1957/58 se anonimnost piscev močno poveča, nakar je glavno kritiško in poročevalsko vlogo Ljubljanskega dnevnika zopet prevzel Rafael Ajlec.

Razlogov za tovrstno kadrovsko menjavanje glasbenih publicistov, ki je bralcem prinašalo tako po formalni kot vsebinski plati različno pisanje o glasbi, ne kaže iskati na tem mestu. Dejstvo, da so bili omenjeni glasbeni pisci razmeroma mladi - Ajlec je kot najstarejši med imenovanimi izjema -, komajda diplomirani na Akademiji za glasbo (Ajlec, Bezić in Kalan 1951.) oziroma brez dokončane formalne glasbene izobrazbe (Loparnik), napeljuje misel $\mathrm{k}$ trem domnevam za menjavanje glasbenopublicističnih peres: poceni »zasilna delovna sila«, politično »preverjeni« ljudje, splet naključij, ki so v Dnevnik prinašala sodelavce $\mathrm{z}$ enako stihijo, $\mathrm{s}$ kakršno jih je kmalu zatem prepuščala njihovim različnim glasbeniškim potem.

\section{Glasbene - zunajglasbene vsebine}

Publicistična merila omenjenih piscev so resda različna, a je bolj kot o kaki profiliranosti glasbenopublicističnih drž treba govoriti o bolj ali manj jasno predpostavljenih, domnevanih, zgolj priložnostno razdelanih kritiških stališčih.

Zanje je značilno, da skušajo glasbo ocenjevati kot avtonomno umetnost, obenem pa so zlasti v prvi polovici petdesetih poudarjene splošne družbeno obarvane glasbene vsebine. Kakršna je že bila uredniška politika je, tako zlasti do sezone 1954-55 in proti koncu petdesetih odmerjala razmeroma veliko prostora za pisanje o lokalnih glasbenih dogodkih, torej o pojavih, ki so zadevali ob splošno politično razpoloženje: revije pevskih zborov, javne produkcije na nižjih glasbenih šolah, prireditve kulturno-umetniških društev, ali pa novice o kulturi in šolstvu (posebej za literaturo in pri filmu); ne nazadnje je bil Ljubljanski dnevnik lokalni časopis, ki je skušal slediti tudi posameznim dogodkom iz cele Slovenije.

Ob kritikah simfoničnih in komornih koncertov ter recitalov bi težko govorili o enovitih vsebinskih, še manj enako dodelanih kritiških in poročevalskih merilih: razen za kritike Rafaela Ajleca in zlasti Boruta Loparnika, kjer so glasbena stališča prefinjeno jasno formulirana, je mogoče domnevati, da so avtorji prispevkov o glasbi ravnali po načelu bolj ali manj elementarnega intuitivnega odziva.

Glasbene teme, ki jih pisci načenjajo ob posameznih koncertih, se glede razmerja med glasbenimi in zunajglasbenimi (političnimi, družbenimi, kulturnimi, ekonomskimi ipd.) do danes niso močno spremenile: poleg nekaterih tehničnih izvajalskih podrobnosti, v osnovi vezanih na tedanje splošno šibko ekonomsko stanje, organizacijskih pripomb ali splošnih glasbeno-kulturniških pomislekov in komentarjev o zasnovi koncertnega pro- 
grama, ocene večidel temeljijo na poustvarjalnih vsebinah in zahtevah izvedenih del, s potrebno večjo pozornostjo odmerjeno izjemnim dogodkom, kot so izvedbe novega (ali prej neizvedenega) dela ali gostovanje tujega izvajalca.

\section{Idejne smernice}

Glede na splošno stihijsko glasbeno politiko Ljubljanskega dnevnika je sicer težko govoriti o jasno formuliranih kritičnih - idejnih in ideoloških - vsebinah. Kljub temu pa je v nekaterih esejističnih prispevkih in predstavitvah glasbenikov ter glasbenih dogodkov mogoče zaslediti jasno podano idejno usmeritev, značilno za tisti čas. Za petdeseta leta je mogoče začrtati tri med seboj prepletena, a bolj ali manj teoretsko ločena miselna vozlišča: nacionalna identiteta, problematika »sodobne glasbe za ljudske množice« in glasba mladih. Čeprav ne sodijo na ožje področje obravnave glasbene publicistike v Ljubljanskem dnevniku, naslednji izbrani primeri vseh treh problematik osvetljujejo ozadje, ki je botrovalo pisanju o glasbi tudi v tem dnevniku.

\section{Nacionalna identiteta}

Rafael Ajlec - tedaj svež diplomant zgodovine glasbe na ljubljanski Akademiji za glasbo - je uradno zadržano izkazovanje nacionalne identitete in poudarjanje pripadnosti širši domovini konec decembra 1951 apostrofiral kot stanje »letargije«, ki se mu je treba upreti in spregovoriti o »slovenskem glasbenem izrazu «. ${ }^{3}$ Videl ga je kot »problem, ki je bistveno zvezan z napredkom naše glasbe«. Ajlečevemu zgodovinskemu pogledu na razvoj slovenske glasbe v tem eseju bi težko ugovarjali. Zamisel o trifaznem »ideološkem razvoju tega problema« - Ajlec namreč postavi tezo, da je o prvi fazi slovenske glasbe mogoče govoriti ob Slomškovem poudarjanju pomena petja v materinščini, o drugi fazi ob strokovnih prizadevanjih čitalnic, ki da so rodile Glasbeno matico, in o tretji fazi ob prizadevanjih Gojmirja Kreka, Novih akordov in zlasti polemike med Antonom Lajovicem in Stankom Vurnikom iz sredine dvajsetih let 20. stoletja ${ }^{4}$ - je morda nekoliko nenavadna, a se zdi vredna vnovičnega premisleka. Za stališče, da se je v prvih desetletjih 20. stoletja »izvršila diferenciacija naše glasbene tvornosti na dva glavna pramena: na tehnično dognano moderno in konservativno čitalniško smer«, je mogoče celo reči, da zajema tudi našo glasbeno sodobnost. Ajlec je namreč od tedanjega skladatelja terjal sintezo obstoječe, kot je jasno poudaril, lažne alternative med modernim, v univerzalnost

3 Rafael Ajlec, O slovenskem glasbenem izrazu. Nekaj zgodovinskih iveri k diskusiji, Ljudska pravica 1951 (29. 12), str. 15.

4 Slomška vidi kot »prvega ideologa tega preporoda«, ki da je razumel pomen petja v materinščini, a za glasbo ni imel posluha; drugi člen v tej verigi, "prvi strokovni vzpon« na področju glasbe, je pripisal čitalnicam in Glasbeni matici, ki jo je rodil čitalniški duh; tretjo fazo razvoja, ki jo nakaže začenši z Gojmirjem Krekom in prizadevanji Novih akordov ter polemiko med Antonom Lajovicem ter Stankom Vurnikom sredi dvajsetih, pa razume kot sicer preseženi, a vendarle aktualni del tudi povojnega časa. 
glasbenega izraza zaverovanim skladateljem in konservativnim, v nacionalni preteklosti živečim glasbenikom: s širokim zgodovinskim pogledom ga je postavil v primež »nove tradicije«, ki na eni strani terja določeno ustvarjalno - in ustvarjalčevo - avtonomijo, medtem ko na drugi strani pričakuje bolj ali manj v folkloro in ljudsko pesem zazrto, »masovno uporabno« glasbo.

Ajlec resda ni odgovoril na vprašanje, kakšna naj bo ta glasba po svojih kompozicijskih značilnostih: »Ne - spet so le skladatelji sami poklicani, da odgovorijo sebi in nam.« Toda $\mathrm{z}$ izredno jasno dikcijo je opozoril in prispeval pomembne »zgodovinske iveri« $\mathrm{k}$ stalnici o nacionalni glasbeni identiteti. O njej je menil, da se je tisti čas še vedno razvijala. Pa ne le razvijala, kot poudari Ajlec: »Danes je [problem slovenskega glasbenega izraza] že bolj zapleten.«

\section{Sodobna glasba za ljudske množice}

Ajlec je s premislekom o nacionalni identiteti v glasbi na specifičnem estetsko-sociološkem postulatu nakazal tisto splošno stanje duha v petdesetih letih 20 . stoletja, za katero so značilne pogosto izrekane, a vsebinsko opredeljive, zlasti v določenih segmentih glasbene produkcije in reprodukcije, glasbene potrebe »novega človeka«. Značilno za slovenske okoliščine pa je Božidar Borko leta 1952 - v Ljubljanskem dnevniku edini pisec, ki se jasno sklicuje na glasbeno politiko - v prispevku z naslovom Občinstvo in glasba kot odgovor na prispevek skladatelja in pianista Marijana Lipovška, podal naslednji oris tega, kar je označil kot

spor, ki se je $\mathrm{v}$ raznih oblikah razvil v zvezi z našo glasbeno produkcijo in zlasti še koncertno politiko je v bistvu spor za občinstvo. Gre za to, ali naj bo koncertno občinstvo, in v širšem smislu tudi glasbeno občinstvo radijskih postaj, samo objekt glasbene politike profesionalistov, ki hočejo imeti predvsem svojemu pojmovanju modernosti ustrezajoče sporede in ki zaradi iskanja novih poti v glasbi mnogo eksperimentirajo, ali pa ima občinstvo pravico terjati, da se njegova potreba glasbenega uživanja nasiča z deli, ki stilno sicer niso zanimiva za profesionalne glasbenike, zato pa govore občinstvu tisto zvočno govorico, ki jo lahko čustveno dojema in s tem tudi vsaj intuitivno doumeva. $Z$ druge strani pa je treba iz glasbenih teženj občinstva izločiti nagnjenje k plehki, lahkotni glasbi in usmerjati njegovo glasbeno doživljanje k resničnim umetniškim kakovostim. Gre potemtakem za problem glasbene vzgoje kar največjega števila glasbeno dojemljivih ljudi. Ta kulturnopolitični interes pa kaj lahko pride navzkriž z glasbeno umetniškimi pogledi in interesi produktivnih in delno tudi reproduktivnih umetnikov. ${ }^{5}$

Borko je svoj esej zaključil s pozivom poklicnim glasbenikom, naj uvrščajo na programe "prvenstveno mojstrska dela ustaljene kakovosti«. (Izbor skladateljskih imen, ki jih v ilustracijo svojih zahtev navaja Borko - Bach, Haydn, Mozart, Beethoven, Schubert, Wagner, Liszt, Berlioz, Debussy, Chopin, Čajkovski, Smetana, Dvoržak, Grieg -, kaže

5 Božidar Borko, Še o vprašanju občinstva in glasbe, Ljubljanski dnevnik 1952 (12. 7.), neoštevilčeno [str. 4]. 
na primerljiv odnos do novosti s tistim, ki ga v obliki dobrohotnih pisem abonentov tudi danes prejema Slovenska filharmonija od poslušalcev, če jih je kaka sodobna skladba iz pretekle sezone posebej presenetila v umetnostno manj tolerantnem vzdušju.) Dejstvo je, da Borkove glasbeno-politične osti

daleč presegajo okvir glasbene stroke in sodijo med najpomembnejše probleme sleherne družbe, ki se po revolucionarnih premikih svojih ljudskih plasti znova oblikuje, upoštevaje [-] mimo nekaterih duhovnih, etičnih in estetskih konstant človeške duševnosti [-] tudi družbena dejstva novega življenja.

Konkretnih povezav med »družbenimi dejstvi novega življenja« in glasbo v Ljubljanskem dnevniku ni mogoče zaslediti v bolj izostreni obliki kot pri Borku, čigar besede nedvomno vsebujejo prizvok tedanjega političnega prepričanja »vodilne stranke«. Nemara pa kaže razumeti kot ironijo zgodovine, da bi bilo o Borkovih »sumljivih namerah« težko govoriti. Ta ljubitelj umetnosti in kulture je 9. januarja $1959 \mathrm{v}$ Ljubljanskem dnevniku objavil zelo pozitivno oceno Slodnjakove Geschichte der slowenischen Literatur, ki je izšla v Berlinu jeseni leta 1958, in v tem natisu videl »najpomembnejši dogodek v naši slavistiki v letu 1958«, čeprav je s tem dregnil v jedro t. i. »Slodnjakove afere«. (Slodnjak - profesor Filozofske fakultete, ki je s svojo avtoriteto predstavljal »eno glavnih trdnjav opozicije « ${ }^{6}$ - je bil politično že prej deležen ne le vrste ideoloških očitkov: leta 1957 je zaradi političnih spletk izgubil svojega asistenta, Franceta Bernika, dve leti za tem pa je bil še prisilno upokojen.) Glede na to, da esejističnih prispevkov o glasbi, ki bi se lotevali tematike o glasbi za množice, in je celo zveza »socialistični realizem« v zvezi z glasbo nekaj, kar je treba iskati na drugih naslovih mimo Ljubljanskega dnevnika, se vprašanje »glasbe za mase« tem bolj izmika jasni opredelitvi, čim bolj ga poskušamo razčleniti na posamezne zahteve. Pri vprašanjih »masovne glasbe« vedno stopa v ospredje idejna drža, ki se upira "napuhu strokovnjaka $^{7} \mathrm{v}$ imenu zlate sredine med modernizmi in tradicionalizmi - edine ustrezne poti za stihijsko glasbeno politiko, namenjeno po Borkovem mnenju množici »glasbeno dojemljivih ljudi«.

\section{Glasba mladih}

Po ukinitvi agitpropovskega aparata leta1956, katerega vlogo je bolj po formalni plati in brez učinkovitih vzvodov moči nadaljevala ideološka komisija SZDL Jugoslavije, je postala poprej omenjena dvojnost med modernizmi in tradicionalizmi, ki jo omenjata tako Ajlec kot Borko, očitno pereča na vseh področjih. Avtorji elaborata, ki ga je sredi leta 1956 izdelala ideološka komisija, tako med drugim ugotavljajo, da »kakšen kulturni ustvarjalec, ki vsaj malo brani svoj ugled, ne sme niti pomisliti na to, da bi skomponi-

${ }^{6}$ Aleš Gabrič, Socialistična kulturna revolucija. Slovenska kulturna politika 1953-1962, Ljubljana, Cankarjeva založba, 1995, str. 284.

7 B.[ožidar] B.[orko], Občinstvo in glasba, Ljubljanski dnevnik 1951 (23. 2.), neoštevilčeno [str. 4]. 
ral popularno pesem, « ker da bi ljudje mislili, da »ta umetnik znižuje svojo kulturno raven ${ }^{8}{ }^{8}$

V Ljubljanskem dnevniku je vprašanje o ustrezni umetniški ravni glasbe - ključno tudi v Ajlečevi in Borkovi omenjeni razpravi - razvidno iz dveh pojavov, povezanih z glasbo mladih. Po eni strani pisci naklonjeno in relativno pogosto spremljajo »lokalne«, nepoklicne glasbene prireditve, kot so javne reprodukcije glasbenih šol. Po drugi strani pa se kaže odnos do »nizke glasbe« najbolj očitno v ducatu poročil, objavljenih o glasbi mladih. Sprva, v začetku petdesetih let, gre predvsem za negativna stališča do jazza, ki se kažejo v obliki polemik v časopisih, poleg Ljubljanskega dnevnika v Ljudski pravici (29. 11. 1951, str. 10), Slovenskem poročevalcu (30. 12. 1951, str. 6; 14. 3. 1952, str. 4; 9. 5. 1952, str. 2) in Mladini (7. 7. 1953, str. 2; 14. 7. 1953, str. 4). Kasneje, od februarja 1956 dalje, ko je potekal ustanovitveni kongres Jugoslovanske zveze skladateljev lahke glasbe v Zagrebu ${ }^{9}$ (mestu, ki je imelo svoje Udruženje kompozitora lake muzike Hrvatske od leta 1954), ${ }^{10}$ pa gre za razumevanje glasbe mladih v širše razumljeni popularni glasbi, ki je vključevala različne zvrsti in sodi seveda tudi na področje »masovne glasbe «. ${ }^{11}$

Ljubljanski dnevnik prispeva k poznavanju odnosa do jazza zgolj vsebinske odtenke, ki jih je mogoče dodati študiji Aleša Gabriča. ${ }^{12}$ Na tem mestu kaže le dodati primer Borisa Urbančiča, ki je v treh nadaljevanjih prispevka z naslovom $V$ čem je moč obrambe jazza ${ }^{13}$ sklenil s svoje strani pol leta poprej načeto javno kritiko jazza v Ljudski pravici. Urbančič je v tej kritiki, ki je bila uperjena proti Vasji Ocvirku in predvsem proti Bojanu Adamiču, prostodušno zapisal:

Od vsega, kar je [Adamič] povedal, je samo eno vredno upoštevanja [...]: poziv, da bi se naši glasbeniki bolj brigali za zabavno glasbo. Vsekakor je ta problem toliko važen, da zasluži večjo pozornost, kakor so mu jo posvečali doslej. ${ }^{14}$

Čeprav je imel jazz tako med akademskimi glasbeniki, kot je bil Karol Pahor, ${ }^{15}$ kot tudi med kulturniki Urbančičevega kova načelne nasprotnike, ki so jih enako motile zabave, ponočevanje in nespodobnost plesa mladih ob jazzu kot estetska elementarnost, je njegovo vlogo v tedanji politiki opredelil Edvard Kardelj leta 1952 rekoč, da ljudje »ne morejo živeti samo od simfonij, ampak morajo imeti tudi neko glasbo, ob kateri se zaba-

8 Nav. po: A. Gabrič, nav. delo, str. 206.

9 Prvi predsednik društva je bil Bojan Adamič. Kulturne vesti. Ustanovni kongres Zveze skladateljev lahke glasbe, Ljubljanski dnevnik 1956 (1.3.), str. 2.

${ }^{10}$ Hrvatsko društvo skladatelja, HDS od utemeljenja, na: http://www.hds.hr/ohds/kronologija hr.ht.

${ }^{11}$ Prim. npr. Rafael Ajlec, Kratko berilo za ljubitelje jazza in za njegove nasprotnike, v: Mlada pota 5 (1956-1957), 3, str. 173-178.

${ }^{12}$ A. Gabrič, nav. delo, str. 102-107.

${ }^{13}$ Boris Urbančič, V čem je moč obrambe jazza, Ljubljanski dnevnik 1952 (8., 9. in 10. 4.), str. 2.

${ }^{14}$ B. Urbančič, V čem je moč obrambe jazza, Ljubljanski dnevnik 1952 (10. 4.), str. 2.

${ }^{15}$ Prim. npr. Karol Pahor, Nekaj o jazzu in njegovem vzgojnem vplivu, Ljubljanski dnevnik 1952 (2. 2.), str. 4. 
vajo«. ${ }^{16}$ Dve leti kasneje je Kardelj še jasneje izjavil: »Jazza ne odklanjamo zato, ker je jazz, marveč odklanjamo samo tiste njegove nezdrave izrastke, ki nimajo več nobene zveze niti z glasbo niti s plesom. « ${ }^{17}$ Tako ne preseneča, da je Ljubljanski dnevnik 1953. objavil prikaz glasbenega življenja na Vrhniki, kjer je status jazza v praksi lepo razviden:

Glasbeno življenje na Vrhniki poživljata še dva jazz-orkestra. Stanovnikov jazz je vključen v Svobodi in goji predvsem plesno glasbo; Pfeiferjev jazz pa je obilo zaposlen s plesno glasbo v Blagajani. Združitev obeh in okrepitev z godalnimi instrumenti pa bi pomenila za Vrhniko ne samo presenečenje, temveč tudi napredek. ${ }^{18}$

Pravzaprav je jazz ${ }^{19}$ v drugi polovici petdesetih vedno bolj postajal del sveta »lahke glasbe «, ki je vključeval še več različnih glasbenih zvrsti. Udeleženci Pogovora v sredo, kot so v Ljubljanskem dnevniku naslovili predstavitev blejskega festivala leta 1960, so bralce opozorili, da je treba »razlikovati zabavne jazz orkestre od tistih, ki spremljajo pevce, oziroma od tistih, ki igrajo čisti jazz «. ${ }^{20}$ Tako je na primer pisec poročila o ljubljanskem nastopu orkestra Glena Millerja koncert pozdravil kot »dogodek prvega reda« za »ljubljanske ljubitelje lahke glasbe«, ${ }^{21}$ čeprav je šlo za četrtega v nizu svetovnih imen jazza, ki jih je organiziralo leta 1953 ustanovljeno Udruženje džez muzičara Srbije ${ }^{22}$ - sledil je koncertom Jutte Hip Comba, Two Beat Stompersov in glasbenikom Dizzy Gillespija, najavljal pa, med drugim, prihod Lambro jazz banda, Modern Jazz Quarteta, Louisa Armstronga in, ne nazadnje, prvi vsakoletni jugoslovanski jazz festival, Jazz festival na Bledu leta 1960, ki ga je tudi Ljubljanski dnevnik toplo pozdravil. ${ }^{23}$

Povzemajoč vprašanje glasbe mladih je mogoče reči, da mimo ohlapno razumljenega jazza in kasneje popularne glasbe v smislu pojmovnih lijakov, v katere se stekajo vsaj popevka, plesna in tista glasba, ki se danes uvršča med popularno, prispevek Ljubljanskega dnevnika k vprašanju o glasbi mladih vidimo predvsem v razmeroma visokem deležu poročanja o zborih in dosežkih mladih šolajočih se glasbenikov po glasbenih šolah, ki so jih odražale na javne glasbene produkcije.

${ }^{16}$ Arhiv Republike Slovenije, ZKOS, f. 17, m. 1, Stenografski zapisnik ustanovnega kongresa ZS, 23. 8. 1952. Nav. po: A. Gabrič, nav. delo, str. 103.

${ }^{17}$ Tretji kongres ZKS, str. 146. Nav. po: A. Gabrič, nav. delo, str. 107.

${ }^{18}$ Glasbeno življenje na Vrhniki, Ljubljanski dnevnik 1953 (10. 7.), str. 4.

${ }^{19} \mathrm{Na}$ primer: leta 1956 je anonimni pisec predstavil tedaj novo zvrst, angleški rock and roll, z naslednjimi besedami, ki lepo prikažejo terminološko ohlapnost: »Britansko otočje je prvo na vrsti. 'Prednja straža' novega 'krika' jazza je že poškodovala nekaj javnih in zasebnih poslopij v več britanskih mestih ter se spopada s stražniki, ki so se ji postavili po robu na 'zmagoviti' poti. [...] 'sprožilo se je v neki filmski dvorani, kjer je bila tretja (in zadnja) predstava filma 'Rock Around the Clock'. "Ljubljanski dnevnik 1956 (4. 10), str. 4.

${ }^{20}$ Pogovor v sredo, Ljubljanski dnevnik 1960 (27. 7.), str. 5.

21 -zz-, Slišali smo orkester 'Glen Miller', Ljubljanski dnevnik 1957 (25. 4.), str. 2.

${ }^{22}$ Miloš Krstić, Vek džeza: od Sent Luisa do Beograda, Beograd, Telos, 2002, str. 294.

${ }^{23}$ Ljubljanski dnevnik 1960 (18. 4.), str. 2; (12. 7.), str. 3; (27. 7.), str. 5; (16. 9.), str. 3; (19. 9.), str. 1 ; (20.9.), str. 3. 


\section{Pogled na dejstva: funkcije in estetske avtonomije}

Preden sklenem z odgovorom na potihem verjetno že postavljeno vprašanje, kaj prispevajo dosedanja navajanja k temi simpozija, je treba strniti rdečo nit o glasbeni politiki, ki spremlja domala vsak stavek tega prispevka.

Če sploh, je o »glasbeni politiki« Ljubljanskega dnevnika mogoče govoriti predvsem z dveh gledišč: pozornost, namenjena lokalnim glasbenim dogodkom, in po deležu koncertnih kritik, ki je primerljiv recimo s tistim, ki ga je Claudia Leyendecker ugotovila ob analizi dveh nemških čezregionalnih dnevnikov za začetek 21. stoletja. ${ }^{24}$ Obe tematiki sta po svoji definiciji usmerjeni k poučevanju, v nekaterih primerih povsem odkrito k prepričevanju o aktualnih dogodkih, torej k političnem delovanju zgolj v najširšem pomenu besede. Toda na podlagi člankov, ki zadevajo ob ta merila, ni mogoče razkriti specifičnih idejnih smernic, ne le zaradi manka esejističnih žanrov, temveč tudi zaradi nestalnosti piscev.

O specifičnem utilitarnem, »porabniškem«, odnosu do glasbe v Ljubljanskem dnevniku ni mogoče govoriti. Glasba se je Ljubljanskemu dnevniku očitno zdela politično preveč obrobna dejavnost, da bi ji posvečali formalno politično pozornost, kakršne je bila deležna predvsem literatura ali kasneje film. Verjetno je razlog za to tudi to, da je tedanje koncertno življenje ostajalo v bolj ali manj jasno odmerjenih tirnicah »srednje poti« med estetskimi postulati glasbenikov, vezanih na različno videno glasbeno - in skladateljsko - avtonomijo, in zgolj okvirno opredeljivimi, bolj ali manj pragmatično pogojenimi pogledi na uporabnost glasbe »glasbeno dojemljivih ljudi«. Šlo je za čas, ko je recimo Lucijan Marija Škerjanec v najavi sezone 1952/53 poudaril, da je izbira koncertnega programa v osrednji slovenski glasbeni ustanovi, Slovenski filharmoniji, prešla iz rok sveta Filharmonije v izključno strokovno presojo dirigentu, ${ }^{25}$ čeprav je podelitev Prešernove nagrade Antonu Lajovcu leta 1954 po izključno strokovnem ključu sprožila »val negodovanja $\ll^{26}$ v politiki. Šlo je za čas, ko je »[n]ajvečji ortodoksnež Boris Ziherl«, glavni partijski ideolog v kulturi do začetka šestdesetih let, videl politične sovražnike

${ }^{24}$ Claudia Leyendecker, Aspekte der Musikkritik in überregionalen Tagszeitungen. Analyse von FAZ un SZ, Europäische Hochschulschriften, Reihe XL, Kommunikationswissenschaft und Publizistik, Band 82, Frankfurt am Main [...], Peter Lang, 2003, zlasti str. 81 ff. Glede primerljivosti kaže poudariti, da je Leyendeckerjeva pri analizah ugotovila 35-odstotni (Süddeutsche Zeitung) oziroma 38-odstotni (Frankfurter Allgemeinen Zeitung) delež kritik koncertov, kar je manj v primerjavi z Ljubljanskim dnevnikom; toda njena analiza zajema tudi recenzije posnetkov (teh je $21 \%$ pri prvem in $27 \%$ pri drugem omenjenem časopisu), kar je smiselno šteti kot vrsto kritiške zvrsti aktualne glasbene ponudbe.

${ }^{25}$ L.[ucijan] M.[arija] Š.[kerjanc], Pred prvim koncertom Slovenske filharmonije, Ljubljanski dnevnik 1952 (17. 10.), str. 2-3. Leta 1953 je morala Slovenska filharmonija reorganizirati tudi poslovanje in postati ustanova $» \mathrm{~s}$ samostojnim financiranjem, t.j. voliti mora po predpisih navedene določbe [Določba predsednika vlade LRS z dne 12. 2. 1953 štev. II-253/3-52] svoj upravni odbor in svoj umetniški svet zato, da bo mogla zaživeti v sodobnih demokratičnih razmerah«. V. K., Sklep Sveta za prosveto in kulturo LRS o Slovenski filharmoniji, Ljubljanski dnevnik 1953 (5. 5.), str. 2.

${ }^{26}$ Arhiv Republike Slovenije, RK SZDLS, f. 38, Zapisnik druge seje komisije za tisk pri predsedstvu SZDLS, 20. 4. 1954, 7. Nav. po: A. Gabrič, nav. delo, str. 175. 
»na vsakem koraku«, ${ }^{27}$ čeprav so se, ugotavlja Aleš Gabrič, v istem času v »vodstvu ZKS uveljavili novi pogledi političnih pragmatikov, predvsem Borisa Kraigherja in Staneta Kavčiča,« ki so menili, »da sodobni umetniški tokovi ne ogrožajo političnega monopola oblasti, in s svojim vplivom izničili doktrino komunistov o ustrezni 'delavski' in 'vrhunski', 'dekadentni' kulturi, ki da prinaša dekadentne vplive buržuaznega Zahoda«. ${ }^{28}$ Šlo je za čas, ko je kljub deklarirani nadnacionalnosti nacionalno ozaveščena politika s pragmatično širokogrudnostjo dopuščala »kvarni« jazz z Zahoda, medtem ko so domači glasbeniki zunaj državnih ustanov na skrivaj »novačili« glasbenike za politično enako nezaželene dejavnosti, kakršni so bili koncerti v ljubljanski stolnici, tudi če je šlo za izvedbo nove kantate uveljavljenega slovenskega skladatelja. ${ }^{29}$

Glasbeni delež Ljubljanskega dnevnika nakazuje to pragmatično (ne le glasbeno) politiko, ki je ravnala po načelu dopuščanja vsega, kar neposredno ne ogroža njenega položaja, predvsem s povsem stihijskim odnosom do piscev. Posledično so tudi prispevki, med katerimi prevladujejo kritike koncertov, odraz vrste okoliščin, ki jih je vprašljivo vezati na druge dejavnike mimo glasbene avtoritete posameznega pisca - ali njegove neprepričljivosti. Delež glasbenih prispevkov razkriva Ljubljanski dnevnik - časopis, ki se je poleg Slovenskega poročevalca edini tisti čas na Slovenskem kolikor toliko sistematično posvečal glasbi - kot glasilo, zadovoljno s takimi poročevalci, kot je zapisal Rafael Ajlec v anketi o glasbeni kritiki leta 1970, ki »imajo še za preveliko vrlino, če se znajo pitijsko izražati in če znajo med vrsticami namigovati na slabosti, premalokdaj pa so pošteno navdušeni.« ${ }^{30}$ Ajlečeva skoraj štirideset let stara priostritev kritike na Slovenskem kot »pitijskega izražanja« o glasbi preusmerja misel stran od konkretnih glasbenih dogodkov v petdesetih letih, od tedanjih okoliščin in odzivov nanje k eni osrednjih estetskih premis, namreč tisti o relativni avtonomiji glasbe.

Na konkretnem primeru: preusmerja jo k vprašanjem o tisti funkciji glasbe, ki je pristojni tudi v času najstrožjega političnega režima na Slovenskem niso mogli, znali ali pa hoteli razumeti kot - tudi - pragmatično uporabno stvar. Kulturnopolitično pristojni tovariši (verjetno v enaki meri zaradi zgodovinske inercije kot formalno razmeroma neurejenih razmer $\mathrm{v}$ glasbenih krogih) ${ }^{31}$ so vztrajali pri domnevi, da je treba nameniti

${ }^{27}$ A. Gabrič, Zajčeva Požgana trava v očeh partijskih ideologov, Nova revija 13 (1994), str. 168.

${ }^{28}$ A. Gabrič, Socialistična kulturna revolucija. Slovenska kulturna politika 1953-1962, nav. delo, str. 6.

${ }^{29}$ Pogovor z Mirkom Cudermanom 2. 9. 2003, posnetek hrani L. S. Sploh se ob rečenem poraja vprašanje, ali je bila Tomčeva kantata, na katero meri zgornja misel, kritično sprejeta samo zato, ker je šlo za »cerkvenega glasbenika«? Prvo od dveh izvedb Requiema G. Verdija v petdesetih letih je kritik pozdravil kot »zdravo in prirodno doživetje toplih in iskrenih čustev, katerih [Verdi] ni zatajil niti v tej religiozni glasbi«. (M. R., Verdijev »Requiem« v Ljubljani, Ljubljanski dnevnik 1951 (5. 10.), str. 2), medtem ko že umestitev tega dela na začetek »ljudskega abonmaja« Slovenske filharmonije zgovorno nakazuje razmerje moči med stroko in politiko v koncertnem življenju. R. Ajlec, Dober start ljudskega koncertnega abonmaja z Verdijevim Requiemom, Ljubljanski dnevnik 1960 (20. 12.), str. 4.

${ }^{30}$ Anketa sodobnosti VII. Ali imamo glasbeno kritiko? Uvodna beseda uredništva, Sodobnost 8 (1970), str. 334.

${ }^{31}$ Leon Stefanija, Totalitarnost režima in glasba, Muzikološke razprave: in memoriam Danilo Pokorn, ur. Nataša Cigoj Krstulović [...], Ljubljana, Založba ZRC, ZRC SAZU, 2004, str. 135-146. 
glasbi zgolj neko pozornost spričo njene relativne avtonomije - ali bolje: avtonomij. Videti je namreč, da glasbene vsebine v Ljubljanskem dnevniku iz petdesetih let - in primerjava s katerim koli današnjim slovenskim časopisom ne bi bila nikakor težavna - terjajo analizo prepletanja več avtonomij in funkcij glasbe: skladateljske avtonomije, avtonomije institucije glasbe kot družbene dejavnosti in, ne nazadnje, avtonomije poslušalca (vključno z vsemi funkcijami, ki jih je mogoče nagovoriti ob vsaki avtonomiji). Ob vseh je mogoče reči, da so prepoznali tudi določeno funkcijo sicer avtonomne glasbe. In zanimivo bi bilo slišati odgovor na vprašanje, ali je glasbena politika Ljubljanskega dnevnika do te mere spoštovala te avtonomije glasbe, da glasbe ni skušala »regulirati«, ali pa je tedaj izvajana glasba tako nepopustljiva pri svojem nihanju med avtonomijami in funkcijami, da je preprosto ni bilo mogoče »regulirati«. V obeh primerih bi bilo potrebno analitični aparat krepko dodelati, da bi odgovorili na vprašanje, ali so danes razmerja med avtonomijami in funkcijami glasbe drugačna, kot so bila tedaj.

\section{Priloga 1}

Ljubljanski dnevnik 1951-1961: vpisi o glasbi

\begin{tabular}{|c|c|c|c|c|c|c|c|c|c|}
\hline $\begin{array}{r}\text { Zvrst } \\
\text { besedila }\end{array}$ & *AK & $* \mathbf{E}$ & ${ }^{*} \mathbf{K}$ & $* \mathbf{N}$ & $\&$ No & $* \mathbf{P}$ & $+\operatorname{Pr}$ & ${ }^{*} \mathbf{R}$ & $\begin{array}{l}\text { Letno } \\
\text { število }\end{array}$ \\
\hline Sezona & & & & & & & & & vpisov \\
\hline 1951-2 & 4 & 7 & 24 & 3 & 5 & 2 & 13 & 1 & 58 \\
\hline $1952-3$ & 7 & 3 & 31 & 12 & 3 & 2 & 39 & / & 97 \\
\hline $1953-4$ & 9 & 4 & 66 & 10 & 4 & 2 & 56 & / & 151 \\
\hline $1954-5$ & 12 & 4 & 74 & 32 & 7 & 3 & 51 & / & 183 \\
\hline $1955-6$ & 2 & / & 44 & 7 & 38 & 5 & 34 & / & 130 \\
\hline $1956-7$ & I & 2 & 7 & 7 & 37 & 1 & 12 & 1 & 66 \\
\hline $1957-8$ & / & 1 & 3 & 17 & 14 & l & 18 & 36 & 89 \\
\hline 1958-9 & I & / & 10 & 41 & 39 & 4 & 15 & 43 & 152 \\
\hline 1959-60 & 4 & 1 & 49 & 41 & 35 & 6 & 35 & 46 & 216 \\
\hline 1960-61 & 2 & 1 & 15 & 60 & 28 & 2 & 16 & 37 & 160 \\
\hline Skupaj: & 40 & 21 & 323 & 230 & 210 & 27 & 289 & 162 & $\underline{1302}$ \\
\hline
\end{tabular}

Število koncertov po

\begin{tabular}{|l|l|}
\hline Leto & \multicolumn{1}{|c|}{$\begin{array}{c}\text { Število } \\
\text { koncertov }^{32}\end{array}$} \\
\hline 1951 & 76 \\
\hline 1952 & 70 \\
\hline 1953 & 81 \\
\hline 1954 & 87 \\
\hline 1955 & $\begin{array}{l}80 \text { (vedno več } \\
\text { snemanj) }\end{array}$ \\
\hline 1956 & $\begin{array}{l}49 \text { (več snemanj kot } \\
\text { koncertov) }\end{array}$ \\
\hline 1957 & $\begin{array}{c}60 \text { (gostovanja v } \\
\text { tujini) }\end{array}$ \\
\hline 1958 & $\begin{array}{c}59 \text { (gostovanja v } \\
\text { tujini) }\end{array}$ \\
\hline 1959 & 69 \\
\hline 1960 & 58 \\
\hline & $\mathbf{6 8 6}$ \\
\hline
\end{tabular}

Legenda: ${ }^{*} \mathrm{AK}=$ abonmajski koncert, ${ }^{*} \mathrm{E}=$ esej, ${ }^{*} \mathrm{~K}=$ kritika, ${ }^{*} \mathrm{~N}=$ najava, $\&$ No $=$ notica, $* \mathrm{P}=$ pogovor, $+\mathrm{Pr}=$ predstavitev skladatelja/dela/dogodka, $* \mathrm{R}=$ radijski + kasneje $\mathrm{TV}$-spored

${ }^{32}$ V seznam Alija Dermelja, ki ga - tako kot za to obdobje manj izčrpen seznam Augusta Pertota - hrani Glasbena zbirka Narodne in univerzitetne knjižnice v Ljubljani, je vključena večina koncertov ljubljanskih glasbenikov in njihovih gostovanj v tujini ter gostov $\mathrm{v}$ Ljubljani. V preglednici niso vštete proslave in snemanja, vključeni pa so poleg vseh običajnih koncertov še mladinski koncerti in vrsta koncertov, ki bi jih mogli uvrstiti pod rubriko »lahka glasba«, ter ponovitve koncertov. 


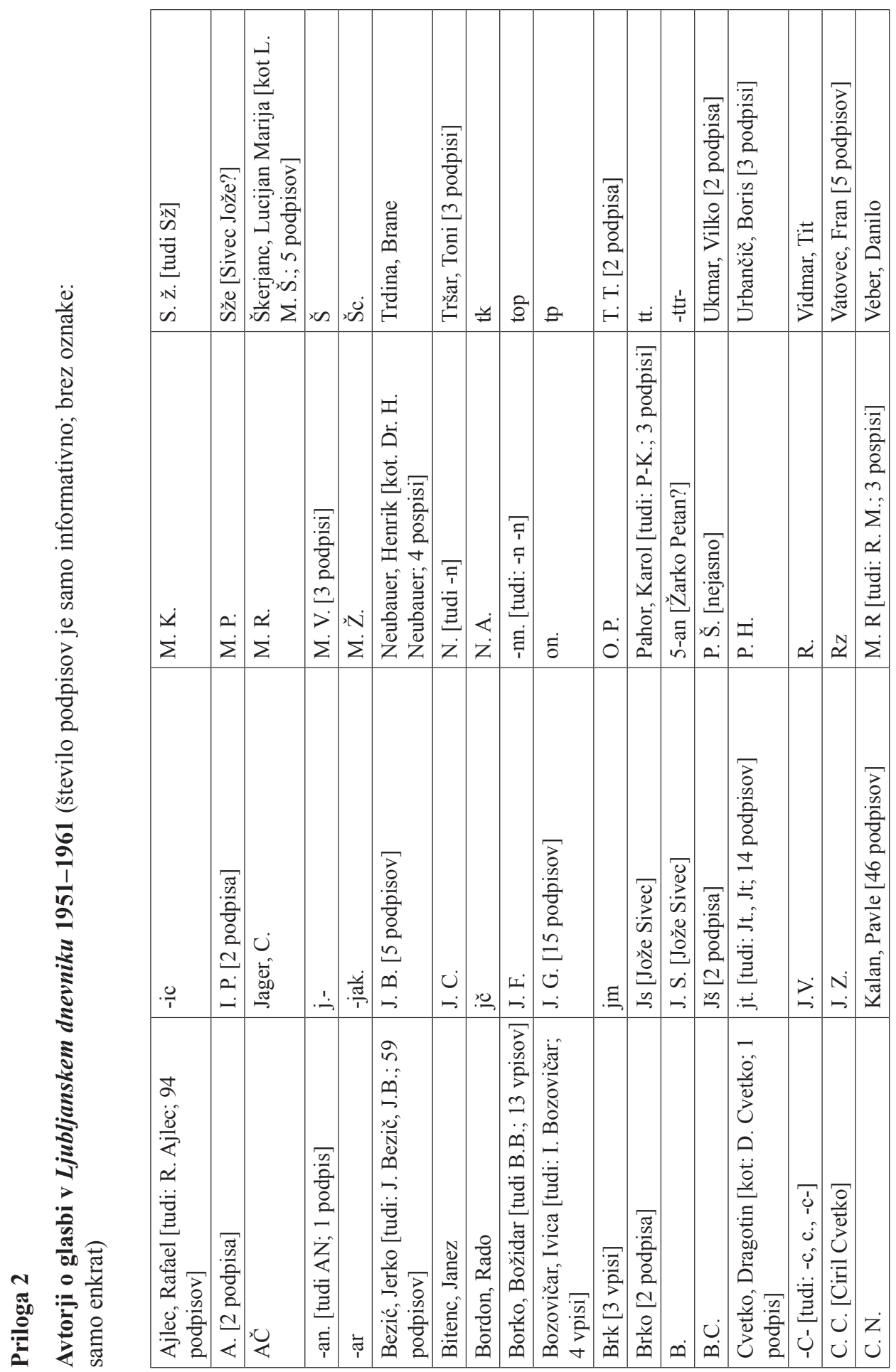




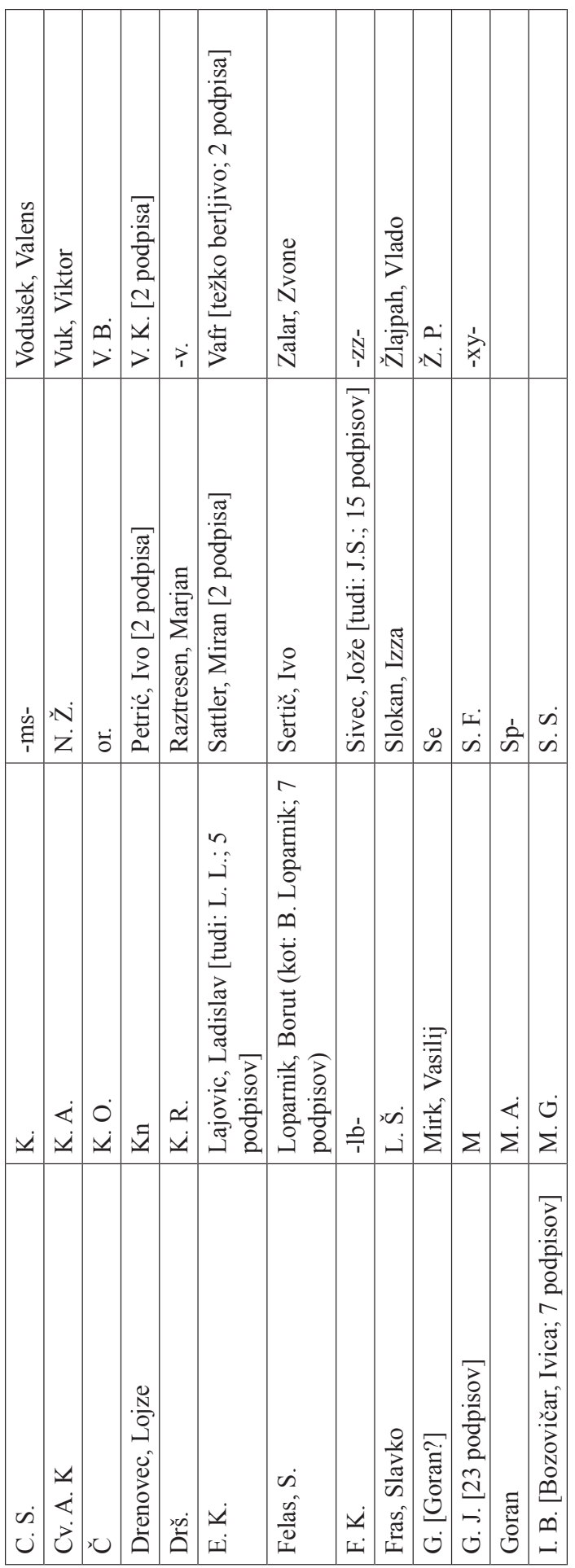


THE RELATIVE AUTONOMY OF MUSIC:

A CASE OF LJUBLJANSKI DNEVNIK 1951-1961

\section{Summary}

The paper aims to sketch the range within which questions of musical functions were addressed in the 1950s through the analysis of a daily newspaper, Ljubljanski dnevnik. This newspaper was chosen for the analysis of the question of musical autonomy versus musical applicability in daily journalism on account of two facts, one material and the other historical. On one hand, when compared with the other dailies of that time, Ljubljanski dnevnik was the only one besides Slovenski poročevalec (later: Delo) in which music - although not in any carefully planned manner - found a place on a regular basis. Conversely, the choice for analysis of Ljubljanski dnevnik arises from the then accelerating process of change that affected cultural and political circumstances in Slovenia. In the decade following the first issue of Ljubljanski dnevnik (it was launched in July 1951), the issue of the "applicability" of music became gradually vaguer. It became intertwined with a complex opposition between notions of the artist's autonomy, aesthetic autonomy and the autonomy of music as a "social fact".

Thus the article is a contribution to the notion of "relative autonomy" of music, since the material analyzed reveals that the main problem regarding the status of music as a functional, as opposed to autonomous, art, was at that time caused by a friction between appreciating music as an activity for which one can expect only "sublime employability" and conceiving music as a pragmatically functional medium. Through the analysis of musical entries in the newspaper Ljubljanski dnevnik and a discussion of what appear to be the main topoi of that time, the article offers an insight into the relations between three sets of questions connecting (and, at the same time, revealing differences between) the notions of musical autonomy and function: 1. the composer's autonomy; 2 . the autonomy of music as a social institution; and 3. the autonomy of the listener. 